\title{
Very Rapid Spontaneous Recanalization of Macrodissected Right Coronary Artery Following Percutaneous Coronary Intervention Associated with Total Coronary Occlusion
}

\author{
Cheng-Gang Zhu, Yuan-Lin Guo, Na-Qiong Wu, Yi-Da Tang, Li-Xin Jiang and Jian-Jun Li* \\ Division of dyslipidemia, Cardiovascular Medicine, Fu Wai Hospital, Chinese Academy of Medical Sciences, Peking Union Medical College, People's Republic of China
}

\begin{abstract}
Coronary artery dissection is a common occurrence after percutaneous coronary intervention $(\mathrm{PCl})$. We here firstly describe a interesting case of very rapid spontaneous recanalization associated with micro-dissection following $\mathrm{PCl}$ in the right coronary artery due to a total occlusion lesion that could not be stented but was associated with very early (a week) spontaneous healing and a favorable outcome.
\end{abstract}

Keywords: Dissection; Coronary artery; Percutaneous coronary intervention

\section{Introduction}

Coronary artery dissection is a common occurrence after percutaneous transluminal coronary angioplasty (PTCA), which has been reported to be visible by angiography in up to $50 \%$ cases following Percutaneous Coronary Intervention (PCI) [1-3]. In the current era of coronary stents, angiographically visible dissection are often routinely stented given the concern for dissection propagation, thrombosis, and total vessel closure $[1,4]$. In fact, prior to the advent of coronary stenting, several studies showed that nonocclusive coronary dissections were only rarely associated with a worsen outcome, and vessels with a greater degree of nonocclusive dissection have a lower restenosis rate than those with lower-grade dissection [5-7]. In some cases, late spontaneous healing of occlusive dissection was also established [8].

Although several studies have examined the outcome of nonocclusive coronary artery dissections in detail, none has addressed the possibility of recanalization associated with macrodissection of coronary artery induced by PCI. Furthermore, it has not been established that how long the healing of dissection lesion could be taken, especially in respect of longer, macrodissection lesion of coronary artery.

We have here reported, a interesting case of rapid healing of a macrodissected right coronary artery following PCI due to chronic total occlusion.

\section{Description of the Case}

A 59-year-old man without history of coronary artery disease was admitted to our hospital because of chest uncomfortness. There was no past medical history of hypertension, hyperlipidemia, or diabetes. His electrocardiogram as well as echocardiogram was normal with an ejection fraction of 54\%. After conventional clinical examination, he underwent a diagnostic coronary angiography at June 23, 2009 in our center, which demonstrated a normal left main as well as anterior coronary artery (Figure 1). However, a lesion with $80 \%$ in the middle of left circumflex artery, and a chronic total occlusion from ostial of right coronary artery were found (Figure 2). Meantime, a left-to-right collateral circulation was observed in the distal of right coronary artery from the distal of left ascending coronary artery (Figures 1 and 2). PCI was successfully performed via a double-wires, contra-lateral injection and seesaw techniques. However, a longer dissection was found from the ostial to middle of right coronary artery following dilatation using a $2.5 \times 20 \mathrm{~mm}$ balloon (Figure 2). In this condition, we stopped the procedure because the patient refused to stenting due to higher cost, and subsequently conventional medications were given to this patient.

Interestingly, a coronary angiography was performed at a week later after PCI, we found that his right coronary artery was rapid recanalization of long dissection lesion (Figure 3). A focal lesion at the proximal of right coronary artery was found, and a $3.0 \times 18 \mathrm{~mm}$ Cypher stent (Cordis Corporation, Miami Lakes, Florida, USA) was implanted (Figure 4). At the same time, a $3.0 \times 23 \mathrm{~mm}$ firebird stent was also placed in his left ascending coronary artery. A follow-up at 1 year, he was doing very well.

\section{Discussion}

Here we have reported an interesting case for the first time of very rapid healing of macrodissection of right coronary artery due to PCI to a CTO that was not stented but have spontaneous recanalization by a week.

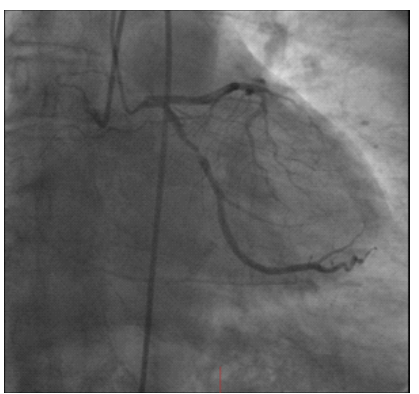

Figure 1: Selective angiography of the left coronary artery system by contralateral injection technique viewed the cranial projection. A CTO in the right coronary artery and a de novo lesion with $80 \%$ stenosis in the left circumflex artery were found.

*Corresponding author: Jian-Jun Li, MD, PhD, Division of Dyslipidemia Cardiovascular Medicine, Fu Wai Hospital, Chinese Academy of Medical Sciences, Peking Union Medical College, Beijing 100037, People's Republic of China, Tel: 86+10+88385397; Fax: 86+10+68331730; E-mail: lijnjn@ yahoo.com.cn

Received November 28, 2012; Accepted December 28, 2012; Published December 31, 2012

Citation: Zhu CG, Guo YL, Wu NQ, Tang YD, Jiang LX, et al. (2012) Very Rapid Spontaneous Recanalization of Macrodissected Right Coronary Artery Following Percutaneous Coronary Intervention Associated with Total Coronary Occlusion. J Clin Case Rep 2:236. doi:10.4172/2165-7920.1000236

Copyright: ( 2012 Zhu CG, et al. This is an open-access article distributed under the terms of the Creative Commons Attribution License, which permits unrestricted use, distribution, and reproduction in any medium, provided the original author and source are credited. 
Citation: Zhu CG, Guo YL, Wu NQ, Tang YD, Jiang LX, et al. (2012) Very Rapid Spontaneous Recanalization of Macrodissected Right Coronary Artery Following Percutaneous Coronary Intervention Associated with Total Coronary Occlusion. J Clin Case Rep 2:236. doi:10.4172/21657920.1000236

Page 2 of 3

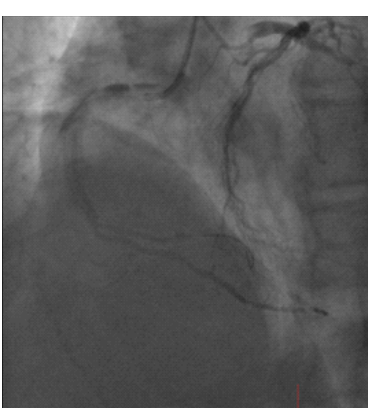

Figure 2: Selective angiography of the left and right coronary artery system by contra-lateral injection technique viewed the left anterior oblique projection. A macrodissection in the right coronary artery were detected following PTCA.

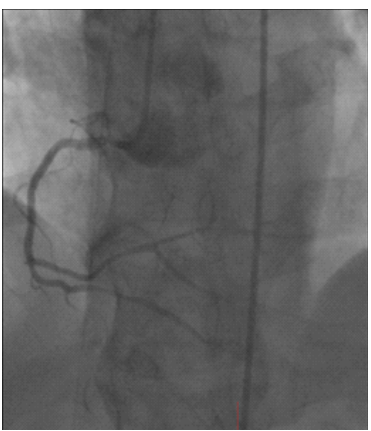

Figure 3: Selective angiography of the right coronary artery system viewed by the left anterior oblique projection (a week later). A rapid recanalization of the right coronary artery was established and a de novo lesion with $80 \%$ stenosis in the ostial of right coronary artery was found.

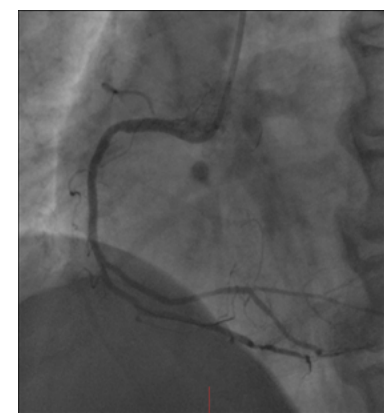

Figure 4: Selective angiography of the right coronary artery system viewed by the left anterior oblique projection (a week later). A 3.0'18 mm Cypher stent was implanted in the ostial of right coronary artery.

Multiple studies performed prior to the era of coronary stenting defined the important relationship between the dissection and clinical outcome [1,9]. Capelletti et al. studied patients with Types A through D dissection following PTCA with angiography at 24 hours and 6 months post-PTCA [9]. All but 2 patients improved their dissection class by 6 months post-PTCA. No adverse clinical outcome was recorded and only 18 patients still had visible dissection. Schroeder et al. studied patients with Types A through C dissection for one year by clinical and angiographic criteria and found that Type $\mathrm{C}$ dissection were associated with a lower rate of clinical events and restenosis [10].

In the current era of increasingly complex coronary interventions, coronary artery dissections are more common occurrence. The most feared complication of a coronary artery dissection is progression to complete vessel closure [1]. It is relatively common in routine practice to stent any angiogaphically visible dissection for fear that this might lead to further more serious complications such as thrombosis and vessel closure. Coronary stents, however, are not without potential consequences of their own. In-stent restenosis, procedural costs, and stent thrombosis remain significant concerns associated additional stent implantation [4]. In our case, we are unable to be stented in his macrodissection lesion in his right coronary artery even in the condition of successfully opening a CTO lesion due to high cost.

With the advent of newer technique and interventional devices, Chronic Total Occlusion (CTO) is being intervened upon with increasing frequency. Kostov and Stankovic reported a substantial coronary artery dissection that occurred as a result of attempted PCI to a right coronary CTO [11]. The patient did not undergo coronary artery stenting. Control angiography at 3 months postprocedure revealed healing of the dissection and continued patency of the right coronary artery. Lorin et al. reported a similar case of attempted PCI to a right coronary artery that resulted in a long dissection with inability to assess the true lumen [12]. The procedure was abandoned and the patient returned 7 weeks later and the found to have a well-healed dissection. The true lumen was then successfully assessed and stenting was performed with excellent angiographic results. This case was very similar to our case, but their second angiography was performed at 7 weeks. Stinis et al. reported a case of a type F dissection following PCI of the distal right coronary artery causing total vessel occlusion that could not be stented but was associated with late (3 months) spontaneous recanalization and a favorable clinical outcome [4]. Although these cases are similar to the case presented here, they differ in that the recanalizations of dissections were found at 7 weeks to 3 months following PCI. In our case, the very rapid healing of macro dissection was found at only a week, indicating recanalization could be happened as early as several days after PCI. To our knowledge, this is the first report showing very rapid healing of a long dissection lesion of coronary artery, indicating a natural healing may be an alternative for a chronic total occlusion of coronary artery disease following PCI.

\section{References}

1. Rogers JH, Lasala JM (2004) Coronary artery dissection and perforation complicating percutaneous coronary intervention. J Invasive Cardiol 16: 493499 .

2. Hsu PF, Lu TM, Leu HB, Chan WL (2005) Double-barrel coronary artery dissection. J Chin Med Assoc 68: 383-385.

3. Porto I, Mitchell AR, Selvanayagam JB, Neubauer S, Banning AP (2005) Percutaneous treatment of simultaneous aortic dissection and pericardial tamponade during coronary intervention. Int J Cardiol 105: 104-107.

4. Stinis CT, Ahsan $\mathrm{CH}$, Movahed MR (2005) Delayed spontaneous recanalization of a totally occluded right coronary artery following failed percutaneous coronary intervention with associated Type F dissection: case report and review. Cardiovasc Revasc Med 6: 174-178.

5. Leimgruber PP, Roubin GS, Anderson HV, Bredlau CE, Whitworth HB, et al. (1985) Influence of intimal dissection on restenosis after successful coronary angioplasty. Circulation 72: 530-535.

6. Alfonso F, Hernandez R, Goicolea J, Segovia J, Perez-Vizcayno MJ, et al. (1994) Coronary stenting for acute coronary dissection after coronary angioplasty: implications of residual dissection. J Am Coll Cardiol 24: 989-995.

7. Nishida T, Colombo A, Briguori C, Stankovic G, Albiero R, et al. (2002) Outcome of nonobstructive residual dissections detected by intravascular ultrasound following percutaneous coronary intervention. Am J Cardiol 89: 1257-1262.

8. Takatsu F, Kinoshita A (1989) Case of spontaneous healing of occlusive dissection on percutaneous transluminal coronary angioplasty. Cathet Cardiovasc Diagn18: 249-254.

9. Cappelletti A, Margonato A, Rosano G, Mailhac A, Veglia F, et al. (1999) Short- 
Citation: Zhu CG, Guo YL, Wu NQ, Tang YD, Jiang LX, et al. (2012) Very Rapid Spontaneous Recanalization of Macrodissected Right Coronary Artery Following Percutaneous Coronary Intervention Associated with Total Coronary Occlusion. J Clin Case Rep 2:236. doi:10.4172/21657920.1000236

and long-term evolution of unstented nonocclusive coronary dissection after coronary angioplasty. J Am Coll Cardiol 34: 1484-1488.

10. Schroeder S, Baumbach A, Mahrholdt H, Haase KK, Oberhoff M, et al. (2000) The impact of untreated coronary dissections on acute and long-term outcome after intravascular ultrasound guided PTCA. Eur Heart J 21: 137-145.
11. kostov J, Stankovic G (2003) Aortic root and extensive coronary dissections complicating recanalization of chronic right coronary artery occlusion: refraining from stenting may have a favorable outcome! J Invasive Cardiol 15: 164-166.

12. Lorin JD, Boglioli JR, Sedlis SP (2004) Successful revascularization of a long chronic total occlusion with blunt microdissection complicated by coronary artery dissection. J Invasive Cardiol 16: 673-676. 